ISSN: $1130-3743$

\title{
LA COMPASIÓN EN LA MORAL DE A. SCHOPENHAUER. SUS IMPLICACIONES PEDAGÓGICAS
}

\author{
Compassion in Schopenhauer's Moral Theory. \\ Its Pedagogical Implications
}

\section{La compassion dans la morale de A. Schopenhauer. Ses implications pédagogiques \\ Pedro Ortega Ruiz y Ramón Mínguez Vallejos \\ Universidad de Murcia. Facultad de Educación. Campus Universitario \\ de Espinardo.30071 Murcia. Correo-e: portega@um.es; rminguez@um.es}

Fecha de recepción: enero de 2007

Fecha de aceptación definitiva: abril de 2007

BIBLID [(1130-3743) 19, 2007, 117-137]

RESUMEN

En este artículo, los autores examinan el concepto de moral y los fundamentos de la misma en la obra de A. Schopenhauer. Para este autor la función de la ética no es la prescripción de normas sobre cómo deben actuar los seres humanos, sino interpretar, explicar y reducir a su fundamento último la muy diversa conducta humana en su dimensión moral. Schopenhauer asigna a la compasión el fundamento de la moral ya que ella es la única que excluye el egoísmo como motivación de la conducta. Y la compasión se ejerce en la experiencia de sufrimiento y carencia del otro; en convertir el sufrimiento del otro en mi sufrimiento. En este artículo se destaca, así mismo, la influencia que Schopenhauer ha ejercido en los filósofos e intelectuales más importantes de los dos últimos siglos y las consecuencias de la ética schopenhaueriana para la educación moral.

Palabras clave: ética, compasión, experiencia, educación moral. 


\section{SUMMARY}

In this article, the authors examine the concept of morality and its foundations in the work of A. Schopenhauer. For this author, the function of ethics is not the prescription of norms on how the human being must act, but to interpret, to explain and to reduce to its ultimate foundation the very diverse human conduct in its moral dimension. Schopenhauer assigns to compassion the foundation of morality since it is the only thing that excludes selfishness as a motivation for conduct. And compassion is exerted in the experience of suffering and deficiency of the other; in turning the suffering of the other into my suffering. This article also emphasises Schopenhauer's influence on the philosophers and intellectuals of the last two centuries and the consequences of Schopenhauer's ethics for moral education.

Key words: ethics, compassion, experience, moral education

\section{SOMMAIRE}

Dans cet article, les auteurs analysent le concept de moral et ses fondements dans l'oeuvre de A. Schopenhauer. Pour cet auteur, la fonction de l'éthique n'est pas de prescrire de normes sur la manière dont les hommes et les femmes doivent agir mais d'interpréter, d'expliquer et de réduire à son dernier fondement, la très diverse conduite humaine dans sa dimension morale. Schopenhauer assigne le fondement de la morale à la pitié puisque celle-ci est la seule à exclure l'égoïsme comme motivation de la conduite humaine. Aussi, la pitié s'accomplit dans l'expérience de la souffrance et du manque de l'autre, dans la transformation de la souffrance d'autrui en la propre souffrance. Dans cet article on souligne, aussi, l'influence exercée par Schopenhauer sur les philosophes et les intellectuels des deux derniers siècles et les conséquences de son éthique sur l'éducation morale.

Mots clés: éthique, compassion, expérience, éducation morale.

Toda buena acción totalmente pura, toda ayuda total y verdaderamente desinteresada que, como tal, tiene su motivo exclusivamente en la necesidad del otro, es verdaderamente, si la investigamos hasta su razón última, una acción misteriosa, una mística práctica, en la medida en que nace del mismo conocimiento que constituye la esencia de toda mística verdadera y no es explicable con verdad de ninguna otra forma... Por eso... he llamado a la compasión "el gran misterio de la ética"

(SCHOPENHAUER, A. Los dos problemas fundamentales de la ética) 
En el Prólogo a la segunda edición de El mundo como voluntad y representación Schopenhauer $(1983,8)$ confiesa que su obra no encontrará el reconocimiento debido entre sus coetáneos. "No a los contemporáneos ni a mis compatriotas, sino a la humanidad entrego mi obra, hoy terminada felizmente, en la confianza de que no la encontrarán inútil, aunque quizás su valor tarde mucho en ser reconocido, pues éste es el destino de todo lo bueno". El hecho de compartir docencia en la misma universidad (Berlín) con Hegel hace que el magisterio de Schopenhauer pase prácticamente inadvertido, oscurecido por la estrella intelectual de aquel momento. Las palabras premonitorias de Schopenhauer tuvieron más tarde fiel cumplimiento. Una de las alabanzas más bellas que quizás se hayan hecho de Schopenhauer ha salido de la pluma de Nietzsche (1996, 151):

Quien haya sentido alguna vez lo que significa encontrar en la mezquina humanidad de nuestro tiempo un ser natural hecho de una pieza, unívoco, suspendido de su propio clavo y móvil, desinhibido y dueño de sí, comprenderá la felicidad y admiración que se apoderaron de mí cuando di con Schopenhauer. Tuve la sensación de haber por fin encontrado al educador y filósofo que durante tanto tiempo había buscado.

El mismo autor describe al hombre schopenhaueriano que asume el sufrimiento voluntario de la veracidad. Sufrimiento que le ayuda a matar su voluntad propia y a preparar la completa transformación e inversión de su ser, cuyo logro constituye el sentido genuino de la vida. Y al compartir con él el ideal de hombre, también comparte con él el ideal de cultura: "Alentar el surgimiento del filósofo, del artista y del santo en nosotros y fuera de nosotros, trabajando así a un tiempo en el perfeccionamiento y la consumación de la naturaleza" (Ídem, 181). En un punto fundamental se aparta Nietzsche de la ética de Schopenhauer, al igual que Kant y Spinoza: en su abierto rechazo a la moral de la compasión. "Este problema del valor de la compasión y de la moral de la compasión (-yo soy un adversario del vergonzoso reblandecimiento moderno de los sentimientos-)..." (Ídem, 234).

El filósofo olvidado de las aulas universitarias ha ejercido, de hecho, una notable influencia en los artistas, intelectuales, filósofos y literatos de los siglos XIX y XX. En concreto, no es posible entender la obra y el pensamiento de los grandes representantes de la Escuela de Frankfurt (Horkheimer y Adorno) sin la construcción moral de Schopenhauer. La obra Materialismo, metafísica y moral de Horkheimer no se hubiera escrito sin el precedente de la compasión como fundamento de la conducta moral de Schopenhauer. Bien es cierto que la compasión en Horkheimer adquiere una dimensión social que en Schopenhauer no existe. La compasión horkheimeriana es denuncia y protesta contra las estructuras sociales injustas que oprimen y hacen imposible vivir en dignidad, y no se reduce a la respuesta compasiva frente al individuo concreto en su situación singular. Es resistencia 
a "lo que no debe ser", a toda forma de dominación y sometimiento, a la tentación de lo absoluto. El dolor de una sociedad herida, atravesada por el sufrimiento está constantemente presente en la obra de Horkheimer y constituye el contenido de toda su moral. La moral en Horkheimer es compasión solidaria con las víctimas de la irracionalidad. En él, la compasión atraviesa la moral de parte a parte. No es un "Complemento", ni un añadido a la justicia como "cuidado" ofrecido a los sujetos vulnerables y humillados. Más bien es una dimensión constitutiva de la moral material que hunde sus raíces en la historia y se hace cargo de la injusticia y del sufrimiento (Horkheimer, 1999). En Schopenhauer, sin embargo, la compasión está muy alejada de todo lo que haga referencia a denuncia de las estructuras sociales injustas. Sólo tiene delante al individuo concreto y singular, no al sujeto que pertenece a una sociedad, al individuo social. Este modo de entender la compasión es del todo ajeno al pensamiento de Schopenhauer. En él tan sólo hay individuos atrapados por el dolor inevitable. Las injusticias empiezan y acaban en los individuos que las producen y las sufren. "El reproche más duro que se hace a los chantajistas codiciosos y a los rufianes legales, sea el de que se han apoderado de los bienes de viudas y huérfanos: precisamente porque estos, al estar totalmente desamparados, deberían haber despertado la compasión más aún que los demás" (Los dos problemas fundamentales de la ética, 1993, 261. En adelante se citará con las siglas: PFE). El mundo humano y el mundo natural en Schopenhauer (1983) es radicalmente injusto. Y cualquier intento de transformarlo no puede sino acabar en el fracaso, pues alteraría su naturaleza. En ésta sólo hay una lucha por la supervivencia en la que cada criatura, impulsada por la voluntad de vivir, se ve obligada a enfrentarse con las demás. Para Schopenhauer, el mal y el sufrimiento son anteriores al individuo, no nacen de la subjetividad, sino de unas condiciones objetivas: No alberga esperanza alguna de que la acción individual o colectiva pueda modificar la realidad que consiste en una repetición sin fin de lo siempre igual.

Otro tanto cabe afirmar de la presencia de Schopenhauer en la obra de Adorno. No ya en el papel de la compasión, como contenido de la moral (que Adorno lo rechaza de plano), sino en la posición que éste adopta frente a la sociedad. La obra adorniana Dialéctica negativa es deudora, en su raíz, del pensamiento de Schopenhauer. La racionalidad crítica que contrapone la razón a la realidad encuentra en Schopenhauer un claro precedente. La realidad no puede identificarse con la razón porque la realidad es irracional. Frente a esta realidad la razón no puede perseguir la identidad sino ejercer la crítica. La actitud crítica de Schopenhauer se traducirá en una dialéctica negativa en Adorno. Para este autor no es posible una vida plenamente justa en una sociedad injusta: "No cabe la vida justa en la vida falsa", escribe Adorno $(2004,44)$. Vivir en justicia no depende únicamente de la voluntad del individuo, porque sólo una sociedad justa permitiría que la vida de sus miembros también lo fuera. Pero lo que en Schopenhauer es motivo de resignación, en Adorno es causa de resistencia y de denuncia. La resistencia a "lo que no debe ser", a toda forma de dominación y sometimiento, a una forma de 
pensar que reduce todo a la identidad, a la inmanencia, a uno mismo, destruyendo con ello el sentido de la diferencia, de lo otro (Adorno, 1975).

Situar a Schopenhauer en el contexto de los filósofos morales no kantianos, antes descritos, nos ayuda a entender mejor su relevante aportación a la construcción ética y a interpretar también las claves del discurso de la moral material emergente y su incidencia en el discurso y la práctica pedagógicos. El conocimiento de las fuentes, el lugar de referencia de lo que pensamos y hacemos en pedagogía, es decir, ubicarse en una tradición de pensamiento significa rotular una determinada propuesta educativa, indicar su orientación, puesto que cualquiera de ellas siempre presupone "algo" y lleva a "algún sitio".

\section{SCHOPENHAUER Y LA MORAL KANTIANA}

Por eso reconozco el especial placer con que ahora procedo a arrancarle a la moral el amplio almohadón, y expreso sin disimulo mi intención de mostrar la Razón práctica y el imperativo categórico de Kant como supuestos totalmente injustificados, sin fundamento y ficticios, de poner en evidencia que también la ética de Kant carece de un sólido fundamento... (PFE, 145).

Estas palabras, ya en el inicio de su ensayo sobre la fundamentación de la moral, muestran la voluntad inequívoca de Schopenhauer de construir una moral sobre presupuestos diametralmente opuestos a los establecidos por Kant.

En el pensamiento kantiano, sostiene Schopenhauer, toda virtud debe derivarse de la reflexión abstracta, del concepto del deber y del imperativo categórico, es decir, de una máxima consciente y abstracta de la razón, al margen de toda inclinación benevolente. El sentimiento de compasión, más que suponer una virtud, es manifestación de debilidad. La ternura, el sentimiento benévolo hacia el otro, la compasión serían un obstáculo para la acción buena en la medida que interfieren en las máximas morales. "El acto para ser bueno y noble, debe darse a regañadientes y por mor de la autoconstricción, teniendo lugar única y exclusivamente por el respeto hacia la ley reconocida como tal y en base al concepto del deber", afirma Schopenhauer en un juicio sobre la ética kantiana (Metafísica de las costumbres, 2001, 153-154. En adelante se citará como: MCO). La exigencia kantiana de que toda acción virtuosa debe tener lugar tan sólo en base al respeto de la ley y conforme a máximas abstractas, de una manera calculadoramente fría y al margen de toda inclinación o sentimiento de benevolencia, a Schopenhauer le resulta tan absurdo como que alguien pretendiera realizar una genuina obra artística obedeciendo únicamente las reglas estéticas. "Esto resulta tan absurdo como aquello" (MCO, 154). Pero es en su obra Los dos problemas fundamentales de la ética en la que el autor elabora un discurso demoledor de la construcción ética kantiana.

Es absolutamente imposible imaginarse una voz imperativa, venga de dentro o de fuera, de otra forma que amenazando o prometiendo: mas entonces, quien la 
obedezca será ciertamente, según las circunstancias, prudente o tonto, pero siempre interesado y, por consiguiente, sin valor moral. El carácter totalmente impensable y absurdo de ese concepto de una obligación incondicionada que se encuentra en el fondo de la ética de Kant surge en su sistema más tarde, concretamente en la Crítica de la razón práctica, al igual que un veneno larvado no puede permanecer en el organismo, sino que al final tiene que irrumpir y desahogarse (PFE, 151).

Para Schopenhauer, el único camino para llegar al fundamento de la moral es la vía empírica; es decir, indagar si se dan acciones concretas en la conducta humana a las que debamos atribuir el valor moral. "El ético, como el filósofo en general, se tiene que contentar con la explicación y elucidación de lo dado, o sea, de lo que realmente existe u ocurre, para llegar a su comprensión" (PFE, 148). Kant admite la existencia de leyes puramente morales ance le lula investigación. Es cierto que existen formas de actuar siempre invariables en la naturaleza, en parte conocidas a priori y en parte observadas empíricamente, a las que denominamos metafóricamente "leyes naturales". Pero también hay una ley para la voluntad humana, la ley de la motivación demostrable e inviolable que lleva consigo la necesidad real: una forma de la ley de causalidad y la "única ley demostrable de la voluntad humana, a la que ésta está sometida como tal" (PFE, 149). Schopenhauer asume la existencia de acciones de valor moral como un hecho empíricamente constatable y señala como función de la ética no la prescripción de normas sobre cómo deben actuar los hombres, sino interpretar, explicar y reducir a su fundamento último la muy diversa conducta de los hombres en el aspecto moral. De ahí que para descubrir el fundamento último de la moral no quede otro camino más que el empírico, o sea, el investigar si es que hay acciones a las que tengamos que reconocer auténtico valor moral" (PFE, 220). Acudir, como hace Kant, a la existencia de una ley moral dada, emparentada con el concepto de deber, mandato, obligación incondicional, etc., nos remite necesariamente a una moral cuyo origen está en el Decálogo, por lo que la moral kantiana es una moral teológica, y su ubicación en la filosofía resulta del todo extraña, "mientras no aporte una legalización válida procedente de la esencia de la naturaleza humana o de la del mundo objetivo... Separados de las hipótesis teológicas de las que proceden, esos conceptos pierden verdaderamente toda significación" (PFE, 150). Una moral, entendida como forma imperativa, como doctrina de los deberes, y la consideración del valor o indignidad de las acciones humanas como cumplimiento o violación de deberes, se ubica necesariamente, como único fundamento, en la moral teológica.

Desde el momento en que, como es el caso de Kant, se emprendió una fundamentación independiente (de la teología) y se quiso consolidar la ética sin supuestos metafísicos, entonces ya no se estaba justificado para asentar en la base, sin otra deducción, aquella forma imperativa, aquel "tú debes" y "es tu deber" (Ídem, 153-154). 
Ya en los inicios de su Metafísica de las costumbres, Schopenhauer afirma el carácter empírico de la moral:

\begin{abstract}
Cuando vemos que un hombre propicia el goce y el provecho ajenos, teniéndolos por algo tan sagrado e inviolable como los suyos propios, experimentamos hacia él, de forma enteramente involuntaria, un sentimiento de aprecio; y viceversa, cuando vemos que alguien persigue ciegamente su goce y beneficio, sin considerar para nada la existencia y los derechos de los demás, experimentamos un acendrado menosprecio hacia él, tanto mayor cuanto nuestros intereses puedan quedar a su merced. Éstos son los únicos hechos relativos a la significación ética del obrar o de la conciencia moral; no existe, sin embargo, deber, precepto, imperativo categórico ni ley moral algunos (Ídem, 3).
\end{abstract}

Kant, a juicio de Schopenhauer, incurre en una petitio principii al tomar la existencia de la ley moral como un hecho dado y no necesitado de una ulterior justificación, y adoptar una ética prescriptiva entendida como doctrina del deber. La ética, para Schopenhauer, tiene un carácter puramente descriptivo, y se limita a explicar y aclarar lo dado. No necesita buscar justificación alguna de sus mandatos porque no los tiene, ni los puede dar.

A ella le basta con investigar si existen acciones de valor moral y cuál es el fundamento de las mismas; y ese fundamento, que deberá ser al mismo tiempo el de la propia ética, no ha de buscarse en ningún tipo de facultad pura o de argumentación apriorística, sino en el único lugar en que se lo puede encontrar: en la experiencia real de la vida y las acciones humanas (López de Santa María, Introducción, PFE, XXXIII-IV).

Schopenhauer acusa, además, a la moral kantiana de ineficaz puesto que la considera incapaz de habérselas con la conducta real del hombre, al ser prisionera de aprióricos castillos de naipes, alejada de los graves apremios de la vida:

...el verdadero impulso a la justicia y la caridad... tiene que ser algo que requiera poca reflexión y aún menos abstracción... y que, independientemente de la formación intelectual, hable a todos incluido el hombre más rudo, se base meramente en la comprensión intuitiva y se imponga inmediatamente a partir de la realidad de las cosas. Mientras la ética no pueda mostrar un fundamento de esa clase, podrá disputar y desfilar en los auditorios: la vida real se burlará de ella (Ídem, 212).

\title{
2. LA COMPASIÓN, FUNDAMENTO DE LA MORAL
}

¿Cuál es entonces el fundamento de la moral? "En todas las épocas se ha predicado mucha y buena moral; pero la fundamentación de la misma ha ido siempre de mal en peor" (PFE, 142), escribe Schopenhauer en 1840, en Escrito concursante sobre el fundamento de la moral. Se trata de un ensayo, no premiado, presentado el 30 de enero de dicho año a un concurso de la Real Sociedad Danesa de las Ciencias 
sobre el Fundamento de la Moral. Para Schopenhauer, la ética todavía busca su fundamentación, su primer principio. Tanto los filósofos antiguos como los modernos han recurrido a los argumentos más diversos, a veces asombrosos, para proporcionar un fundamento demostrable a las exigencias de la moral. Todos los intentos, hasta ahora, han sido en vano, quizás porque se ha despreciado el camino más natural. Y éste, para Schopenhauer, es el principio demostrable de una ley natural: la ley de la motivación.

Pero también, escribe Schopenhauer, hay una ley para la voluntad humana, en la medida en que el hombre pertenece a la naturaleza; y una ley, por cierto, estrictamente demostrable, inviolable, sin excepción, inquebrantable, que lleva consigo la necesidad, no vel quasi, como el imperativo categórico, sino realmente: es la ley de la motivación, una forma de la ley de causalidad, o la causalidad mediada por el conocer. Ésta es la única ley de la voluntad humana, a la que ésta está sometida como tal. Dice que cada acción sólo puede producirse como consecuencia de un motivo suficiente. Es, como la ley de causalidad en general, una ley natural (PFE, 149).

Si no hay acción humana sin una motivación suficiente, ésta puede venir de la obligación incondicional de cumplir con un mandato (imperativo categórico) que, o bien se traduce en miedo al castigo, o bien en búsqueda de recompensa, porque es absolutamente imposible imaginarse una voz imperativa, venga de dentro o de fuera, de otra forma que amenazando o prometiendo: mas entonces, quien la obedezca será ciertamente, según las circunstancias, prudente o tonto, pero siempre interesado y, por consiguiente, sin valor moral" (PFE, 151). La obligación incondicionada no puede ser un concepto ético fundamental; necesariamente está referida a un premio o a un castigo y, por lo mismo, es necesariamente egoísta, por lo tanto carente de valor moral. ¿Qué motivación humana podría constituir, entonces, el fundamento de la moral? Schopenhauer afirma que lo que mueve a la voluntad es el placer y el dolor en general. Todo motivo, por tanto, tiene que tener una relación con el placer y el dolor. Pero aquella acción cuyo fin último sea el placer y el dolor del agente mismo es un fin egoísta, sin valor moral. Egoísmo y valor moral en una misma acción se excluyen entre sí absolutamente. "Si una acción tiene como motivo un fin egoísta, no puede tener ningún valor moral: si una acción ha de tener valor moral, ningún fin egoísta inmediato o mediato, próximo o remoto, puede ser su motivo" (PFE, 231).

Pero si el placer y el dolor propios no pueden ser el fin último de una acción moral, ¿dónde ubicar, entonces, el placer y el dolor? Para Schopenhauer, la acción debe producirse únicamente en razón del otro, «entonces su placer y dolor tienen que ser inmediatamente mi motivo: igual que en todas las demás acciones lo son los míos" (PFE, 252). Esto supone convertir el placer del otro en mi propio placer y su dolor en mi dolor; convertir al otro en el fin último de mi voluntad.

Eso supone necesariamente que yo com-padezca (mit leide) directamente en su dolor como tal, que sienta su dolor como en otro caso sólo siento el mío y que, por lo tanto, quiera inmediatamente su placer como en otro caso sólo el mío. Mas 
eso requiere que de alguna manera esté identificado con él, es decir, que aquella total diferencia entre mí y todos los demás, en la que precisamente se basa el egoísmo, sea suprimida al menos en un cierto grado (PFE, 232-233).

Schopenhauer rompe abiertamente con la tradición kantiana que considera que todo lo bueno y noble debe provenir de la reflexión. "Todo amor verdadero y puro supone propiamente la compasión, y aquel amor que no sea compasión no es sino egoísmo. El egoísmo es el eros, la compasión es el agapé» (MCO, 155). Con ello, Schopenhauer introduce de lleno la compasión como fundamento de la moral, y el fundamento de la moralidad en la misma naturaleza humana. Intencionadamente deja fuera de toda consideración la maldad (que hace del dolor ajeno su fin último) como móvil de la conducta humana, porque todas las acciones provenientes del mismo a todas luces son reprobables éticamente. Y centra su atención en la compasión como fundamento de la acción moral, y no en la felicidad y el gozo por el bien ajeno. Y la razón de ello es que el dolor y el sufrimiento, la carencia, la privación y la necesidad “es lo inmediatamente sentido. En cambio, la naturaleza de la satisfacción, del placer, de la felicidad, consiste solamente en que una privación es suprimida y un dolor acallado" (PFE, 235). Sólo el sufrimiento y el dolor del otro suscitan directamente en nosotros el sentimiento de compartir el dolor, de com-pasión (cum pati-padecer con). Por el contrario, la persona feliz y satisfecha, aunque nos agrade su situación, nos deja indiferentes.

Inmediatamente no nos es dado más que la privación, es decir, el dolor. Pero la satisfacción y el goce son conocidos inmediatamente por el recuerdo del dolor y de la privación pasados, que cesarán a la aparición de aquéllos. De aquí que no sintamos ni apreciemos bastante los bienes y ventajas que poseemos, sino que creemos que son como deben ser, pues no nos hacen felices más que negativamente, apartando de nosotros el dolor. Sólo después de haberlas perdido conocemos su valor, pues la necesidad, el dolor, la privación es lo único positivo, lo que sentimos inmediatamente (Schopenhauer, 1983, 249-250).

La persona feliz, la que goza de la vida no nos excita ni nos mueve pura e inmediatamente a participar de su felicidad, como nos excita y nos mueve pura e inmediatamente a participar de su sufrimiento el que carece, sufre y es desgraciado (PFE).

Schopenhauer describe cómo el sufrimiento del otro nos puede mover a obrar o dejar de obrar. O bien como contención para no causar daño al otro, y en este caso se identifica con la justicia, o bien como impulso para la ayuda activa, para aliviar el dolor del otro, y entonces se traduce en caridad. Ambas virtudes tienen su origen en la compasión natural: no ofender y ayudar para no hacer sufrir o aliviar y suprimir el sufrimiento del otro. La compasión no se basa, por tanto, en principios religiosos, dogmas o mitos; es, por el contrario, un hecho innegable de la conciencia humana, es esencialmente propia de ella, "es originaria e inmediata, se encuentra en la misma naturaleza humana, justamente por ello tiene solidez en toda situación y se muestra en todos los países y épocas" (PFE, 237), y proviene del 
conocimiento del sufrimiento ajeno, el cual nos resulta comprensible de inmediato en base a nuestro propio sufrimiento, al que venimos a equiparar el ajeno. Compadecemos "en la medida en que nos reconocemos a nosotros mismos en la persona ajena" (MCO, 153). La primera manifestación de la compasión tiene un carácter de justicia en tanto se opone represivamente al sufrimiento que se puede causar a otro. "La misma compasión me retendrá de buscar la satisfacción de mis apetitos a costa de la felicidad de la vida de los individuos" (PFE, 238). Pero la compasión no sólo me retiene de ofender al otro, me impulsa también a ayudar, a aliviar y suprimir su sufrimiento. "La compasión no sólo me retiene de ofender al otro, sino que me impulsa a ayudarle" (PFE, 251). Esta participación totalmente gratuita y desinteresada, hasta instintiva, en el sufrimiento del otro, es la única fuente de moralidad de nuestras acciones, si es que tienen algún valor moral, "es decir, si han de estar depuradas de todos los motivos egoístas y si, justamente por ello, han de despertar en nosotros mismos aquella satisfacción interna a la que se llama conciencia moral buena, satisfecha y aprobatoria" (PFE, 252). Sólo el fin "puramente objetivo de que quiero ver al otro auxiliado, arrebatado de su necesidad y aflicción, y liberado de su sufrimiento" (Ídem, 252-253) es lo que hace que nuestra conducta tenga valor moral.

¿Y cómo es posible, se pregunta Schopenhauer, que un sufrimiento que no es el mío, que no me afecta, se convierta para mí en un motivo de forma tan inmediata y me mueva a obrar? Esta pregunta encuentra en Schopenhauer una respuesta sorprendente. Es un proceso "misterioso", llega a decir, cómo yo puedo sentir como mío el sufrimiento del otro; cómo su dolor, su necesidad pueden convertirse en motivo para mí. "Ese proceso es, lo repito, misterioso: pues es algo de lo que la Razón no puede dar ninguna cuenta inmediata y cuyos fundamentos no se pueden averiguar por vía de experiencia. Y, no obstante, es cotidiano" (PFE, 254). Es el mayor misterio de la ética, constituye su fenómeno primordial y originario. Semejante proceso le parece "asombroso y hasta misterioso. Es, en verdad, el gran misterio de la ética, su fenómeno originario y el mojón más allá del cual la especulación metafísica no puede atreverse a dar un paso" (PFE, 233). Y siendo el sentimiento de la compasión algo cotidiano del que derivan los otros deberes de la justicia ("no hagas daño a nadie") y los deberes de la caridad ("ayuda a todos cuanto puedas") y, a la vez, algo tan decisivo para la vida moral del individuo, no encuentra, sin embargo, el autor otra explicación que la de ser un proceso "misterioso" que está en manos de cada sujeto.

La ética es, en verdad, la más fácil de todas las ciencias, tal y como es de esperar; porque cada uno tiene la obligación (obliegenheit) de construirla por sí mismo y, a partir del principio supremo que radica en su corazón, deducir por sí mismo la regla para cada caso que se presente... La compasión, como el único móvil no egoísta, es también el único auténticamente moral, resulta, de una forma extraña y hasta casi incomprensible, paradójica (Ídem, 255).

Este recurso a lo "misterioso, extraño y paradójico" de la compasión nos recuerda a Levinas (1991), sin que pueda hablarse de influencia, cuando acude a 
la "VOz de la conciencia ética" como impulso para la conducta moral. En ambos autores no se trata de la escucha de un "oráculo en sí mismo". No es un principio universal y abstracto que sirva como base para volverse hacia las singularidades de cada individuo, sino que a este sujeto, interpelado por la situación concreta del otro, le viene impuesta la obligación de responder, sin posibilidad de dilación, so pena de negarlo y caer en la inmoralidad. Tanto en Schopenhauer como en Levinas (1991) la moral es an-árquica, no está referida a un principio previo universalmente válido, no demanda el respaldo de una ley moral universal que nos dicte qué debemos hacer en situaciones singulares.

Poseemos una consciencia moral, una conciencia en sentido estricto. Pero dicha consciencia moral no ostenta en modo alguno la forma de un imperativo, de un dictado relativo a "lo que uno debe hacer y a lo que uno debe dejar de hacer"; tal fue el parecer de Kant, pese a que no lo probó, y desde Kant todos lo han repetido, por lo cómodo que resulta, aunque lo vengan a expresar de un modo ligeramente distinto (Ley moral). Sin embargo, nadie dará con semejante precepto, mandato o deber en el seno de nuestra consciencia (MCO, 3).

La moral en Schopenhauer no empieza por la voluntad de poner en práctica principio moral alguno, sino por dejarse atrapar por el sufrimiento del otro, por el imperativo de aliviar o mitigar su suerte.

La posición de Schopenhauer sobre la compasión como origen y contenido de la moral podría suscitar, a más de un lector, una pregunta: ¿La conducta moral se da sólo en la respuesta compasiva ante el sufrimiento del otro? En otras palabras: ¿Puede darse una conducta moral (es decir, responsable) ante un sujeto no sufriente o no necesitado de compasión? Para nosotros, la respuesta moral (de responsabilidad) no acontece sólo ante la experiencia de sufrimiento de otro (alguien) que demanda compasión. La experiencia no necesariamente tiene que ser «negativa" para demandar una respuesta moral. El otro, desposeído y vulnerable, se me "impone", como diría Levinas, en la desnudez de su rostro, desde la sola condición de ser humano vulnerable, no por su condición actual de sujeto sufriente. No es sólo el dolor, ni la carencia o el sufrimiento del otro los que generan una relación ética-moral, de tal modo que en la ausencia de éstos no sea posible la conducta moral. La respuesta moral, que se traduce en reconocimiento y acogida del otro, se da en el encuentro con la singularidad de una persona en la circunstancia concreta en la que está viviendo (Levinas, 1993). Es decir, se responde del sujeto histórico en todo lo que éste es, en su aquí y en su ahora. La moralidad (responsabilidad) es una exigencia de la dignidad de este sujeto concreto y singular que se traduce en prohibición y mandato (No Matarás), cualquiera que sea la "condición" en que éste se encuentre. "Por eso, la primera palabra del rostro es de resistencia ante la querencia cainita del hombre: no reducirás mi identidad diferente a tu mismidad, no alimentarás tu voraz conciencia con mi desvalida desnudez, no me convertirás en objeto de tu conocimiento" (Mate, 1997, 72). La respuesta moral es, por tanto, incondicionada, inapelable, como diría Levinas. Al Yo le es infligido un 
imperativo de tener que responder del otro; imperativo que él no ha elegido, ni ha querido. "El otro "lo" reclama y, a partir de entonces, cueste lo que cueste, no puede pasar delante de él indiferente a su suerte, por mucho que se preocupe por la de la humanidad" (Chalier, 2002, 52). En Schopenhauer, sin embargo, no es posible la moral sin compasión. Y la razón estriba en que no existe un ser humano que no necesite compasión. Su existencia "representa un perpetuo tránsito hacia la muerte, un continuo morir, dado que nuestra vida pasada... se halla enteramente finiquitada y muerta, puesto que ya no existe» (MCO, 54). Para Schopenhauer, el presente no existe sino en relación al pasado, y el futuro es pura incertidumbre y brevedad. "En este orden de cosas, la existencia del individuo... supone la continua precipitación del presente sobre el difunto pasado, un constante morir" (Ídem, 55). Si la vida para Schopenhauer oscila entre el dolor y el hastío, hasta el punto de que ambos representan sus últimos elementos constitutivos, es lógico, entonces, "que la propia muerte se vuelva apetecible, y uno acude(a) voluntariamente a su encuentro, en el marco de la huida en que consiste toda la vida" (Ídem, 56). Más aún, si "lo único que nos es dado originaria e inmediatamente es la carencia, esto es, el dolor" (Ídem, 63), y se afirma, además, que "la vida humana no es susceptible de una auténtica felicidad atendiendo al conjunto de su esencia, sino que más bien ésta puede ser descrita como un polimórfico sufrimiento y un estado en absoluto deseable, un estado cuya finalidad no sería ni mucho menos la de hacernos dichosos y al que le cuadraría mejor el calificativo de desventuradon (Ídem, 68), se entenderá, obviamente, que para Schopenhauer, la única relación moral (no egoísta) que cabe con otro ser humano sea la compasión.

En la compasión de Schopenhauer se puede formular una segunda pregunta: ¿Es una compasión libre de todo egoísmo? A propósito del "llanto" Schopenhauer nos da la clave del sufrimiento con el otro o por el otro:

Cuando lo que nos mueve al llanto no es el sufrimiento propio, sino el ajeno, ello se debe a que, en la imaginación, nos ponemos vivamente en el lugar de quien sufre o, así mismo, a que en su sino vislumbramos la suerte de toda la humanidad $\mathrm{y}$, por consiguiente, ante todo también la nuestra, con lo que, tras un largo rodeo, siempre acabamos llorando por nosotros mismos, en tanto que nos compadecemos de nosotros mismos (MCO, 157).

Schopenhauer salva esta aparente dificultad mediante el desbordamiento del principium individuationis que nos impide la diferenciación egoísta entre la propia persona y la ajena a través de la equidad y la generosidad. "Sólo esta superación elimina la diferenciación entre el propio individuo y el ajeno, posibilitando con ello esa perfecta bondad del ánimo que llega hasta el afecto desinteresado y el magnánimo autosacrificio por los demás» (MCO, 159). Sólo el individuo altruista, dispuesto a sacrificarse a sí mismo para que otros puedan salvarse, merced a dicho sacrificio, puede reconocer en todos los seres su mismidad más íntima y auténtica y considerar los interminables sufrimientos de todo ser vivo como suyos propios. «En lo sucesivo ningún sufrimiento deja de resultarle ajeno... Todo sufrimiento de 
otro, que él ve y raramente logra mitigar, todo sufrimiento del que tiene noticia indirecta e incluso todo el que presume como meramente posible, inciden en su ánimo como si fueran sufrimientos propios" (Ídem, 160).

Por último, podemos hacernos aún otra pregunta: ¿El sentimiento de compasión nos lleva a un irracionalismo romántico? Para Schopenhauer, al igual que para Horkheimer, la moral no es un imperativo de la razón, un "hecho de la razón pura", pero tampoco es un impulso ciego o un sentimiento irracional. Brota de la experiencia material de sufrimiento del individuo concreto. Es un sentimiento "cargado de razón", pero de una racionalidad que difiere de la ley natural del egoísmo. Y se vuelca al necesitado para aliviar y poner fin al sufrimiento. Es un sentimiento racional "de otro modo" a como lo es la razón dominante, que no habla a favor de la moral, que no señala en la dirección en la que impulsa hacia delante el sentimiento moral, sino en el sentido del egoísmo y del poder (Sánchez, 2001). En este sentido, es un sentimiento racional que pone en movimiento a la razón desde el mismo suelo, en la misma historia de sufrimiento y carencia del ser humano concreto.

Aunque los principios y el conocimiento abstracto en general no son de ningún modo la fuente o el fundamento de la moralidad, a una conducta moral le resultan imprescindibles como el depósito, el réservoir en el que se conserva el ánimo que nace de la fuente de toda moralidad, la cual no fluye en todo momento, para, llegado el caso de la aplicación, fluir a través de canales de derivación (PFE, 239).

Sin principios, como escribe Schopenhauer, quedaríamos irresistiblemente a merced de las impresiones externas, sin la posibilidad de ejercer ningún autodominio sobre nuestra conducta. Estaríamos entregados sin defensa a la impresión y el afecto, y entonces ninguna moralidad consciente sería posible (PFE).

\section{LA EXPERIENCIA EN LA PEDAGOGÍA dE LA COMPASIÓN}

En Schopenhauer es inútil buscar un discurso pedagógico, aunque Nietzsche viera en él el prototipo del educador. Sus obras, sin embargo, no pretenden hacer pedagogía, ni tienen una intención educadora. Ni siquiera cuando habla de las virtudes de la justicia y la caridad se sale, en un excursus, del guión previamente establecido para, al menos, dibujar algunos trazos sobre la enseñanza de dichas virtudes. Para Schopenhauer, la ética tiene una finalidad exclusivamente descriptiva: investigar si es que hay acciones a las que tengamos que atribuir valor moral. Su preocupación es fundamentar la moral, no señalar ni proponer vías y estrategias para la educación moral de los individuos. Semejante propósito educativo excede las pretensiones de Schopenhauer. Tampoco en Horkheimer y Levinas hay discurso pedagógico alguno dirigido a la educación de las jóvenes generaciones, a pesar de su experiencia desgarradora en el totalitarismo nazi. Sólo Adorno, excepcionalmente, escribe un artículo: "La educación después de Auschwitz". Sin embargo, el pensamiento de estos autores ha inspirado un discurso pedagógico 
que se ha traducido en propuestas educativas que tienen a la experiencia de los educandos y al contexto histórico en que éstos viven como inexcusable punto de partida. El reciente discurso de la pedagogía de la alteridad (Ortega, 2004) hunde sus raíces en estos autores; y la corriente personalista en educación se reconoce en la filosofía de Mounier, Lacroix, Buber y otros. De Schopenhauer, sin embargo, ninguna corriente pedagógica se considera deudora en sus propuestas educativas. Es el gran desconocido, a pesar de la fuerte influencia que su pensamiento ha ejercido en los principales filósofos, literatos, intelectuales y artistas de los siglos XIX y XX. No se puede decir lo mismo de Hegel, contemporáneo de Schopenhauer, cuya presencia se hace evidente, desde el idealismo, en el pensamiento y práctica pedagógicos. Por ahora, nos limitamos en este trabajo a exponer las implicaciones pedagógicas de la ética schopenhaueriana, dejando para un estudio posterior propuestas concretas en la educación moral que se reconocen en el pensamiento de Schopenhauer.

¿De qué "experiencia" habla Schopenhauer? En Schopenhauer la compasión sólo se puede ejercer con aquellas personas que sufren. Sólo el sufrimiento, la carencia, el peligro y el desamparo del otro suscitan directamente en nosotros la compasión. "El feliz y satisfecho nos deja como tal indiferentes" (PFE, 235). Se trata, entonces, de una experiencia negativa. No com-padecemos a la persona feliz, a la que goza y disfruta del éxito. Con ésta nos alegramos. Pero Schopenhauer pone el fundamento de la moral en la compasión hacia el otro, en padecer con el otro. Es decir, en una motivación libre de toda sospecha de egoísmo. Y sólo el que sufre con y por el otro no busca su propio bien, ni directa ni indirectamente. De este modo, sólo el que compadece actúa moralmente. Educar para una vida moral es, entonces, educar para compadecer.

La doctrina de Schopenhauer, que acabamos de exponer, tiene unas claras consecuencias en la práctica de la educación moral. A saber: sólo se educa moralmente desde y en la experiencia. Pero no sirve cualquier experiencia, ésta ha de ser negativa, es la experiencia ante el sufrimiento o carencia de alguien, por tanto subjetiva, concreta y contextual. Quedaría, de este modo, excluida la reflexión y búsqueda del "mejor argumento" como recurso didáctico privilegiado para la educación moral, tal como defiende la pedagogía cognitiva de raíces kantianas. Para la conducta moral, es decir, para compadecer no es necesario justificar ni explicar, con razones o argumentos, la "bondad" de lo que se hace. Acudir a la razón, privada de sentimiento, como fuente última para garantizar la moralidad de una conducta constituiría una ofensa hacia la persona que demanda una respuesta de ayuda y cuidado. "Para el descubrimiento de la compasión, mostrada como la única fuente de las acciones desinteresadas y, por tanto, como la verdadera base de la moralidad, no se precisa de ningún conocimiento abstracto sino sólo del intuitivo, de la mera captación del caso concreto a la que se reacciona inmediatamente sin ninguna mediación ulterior del pensamiento" (PFE, 270). Schopenhauer suscribiría las palabras de Adorno sobre la educación: "La exigencia de que Auschwitz no se repita es la primera de todas en la educación. Hasta tal punto precede a cualquier 
otra que no creo deber ni poder fundamentarla. No acierto a entender que se haya dedicado tan poca atención hasta hoy. Fundamentarla tendría algo de monstruoso ante la monstruosidad de lo sucedido" (Adorno, 1973, 80). La sola reflexión o razonamiento sobre el "deber" de responder a la demanda del otro hace recaer el fundamento de la conducta no en el bien del otro, sino en la rectitud de mis argumentos. Y esto en Schopenhauer es inmoral por ser egoísta.

La educación moral de raíz kantiana encuentra en la doctrina schopenhaueriana una fuerte crítica. El desarrollo de habilidades discursivas, a partir de la teoría de Kohlberg sobre el desarrollo del pensamiento moral, se muestra incapaz de dar cuenta de la conducta moral. Actuar virtuosamente no está vinculado a un discurso moral.

Uno puede lograr hacer virtuoso a un hombre mediante lecciones de moral o prédicas en tan escasa medida como todas las doctrinas estéticas, desde Aristóteles hasta nuestros días, han servido para forjar un solo poeta... Pues el concepto, que ya descubrimos infructuoso para el arte, se muestra igualmente estéril para la auténtica e íntima esencia de la virtud (MCO, 140).

La conducta moral no se explica, ni acontece por "lo que pensamos" acerca de ella, sino porque nos sentimos conmovidos, padecemos en nosotros, la situación real de aquel que tenemos delante. La resistencia a aceptar el sufrimiento del otro o la no-indiferencia hacia el necesitado constituye no sólo el impulso para la conducta moral, sino que la ayuda, el hacerse cargo del otro, la caridad o agapé, en palabras de Schopenhauer, es el contenido mismo de la moral, porque sólo esta conducta tiene valor moral. No está en mí la iniciativa en la acción moral, sino en el otro que me demanda o suplica que no cierre los ojos a su sufrimiento. El otro no es un mero pretexto para poder actuar moralmente, sino quien me constituye en sujeto moral, como diría Levinas.

En Schopenhauer la moral es también, al igual que en Horkheimer, Adorno y Levinas, heteronomía. Es súplica, prohibición y mandato. Los principios abstractos o máximas morales que prescriben, por sí solos, conductas valiosas son del todo ajenos en Schopenhauer. No hay una ley moral que esté presente en nosotros desde el principio, desde antes de que la experiencia nos sitúe ante conflictos que debamos resolver con ella. Si no es así, la educación moral sólo debería preparar, equipar a los educandos para responder a las experiencias de sufrimiento y de necesidad del otro. O lo que es lo mismo: educar para compadecer.

Se ha querido ver cierta dependencia o proximidad de la pedagogía del cuidado, de la atención (care) con la ética de la compasión. En la ética schopenhaueriana no se justifica, al menos no encuentra en ella su fundamento, dicha pedagogía que en los últimos años ha cobrado actualidad de la mano de Van Manen. En sus obras más conocidas: El tacto en la enseñanza (1998) y El tono en la enseñanza (2003) el autor expone otro modo de entender y hacer la educación que, sin romper con otros enfoques tradicionales, resalta la necesidad de poner en práctica la sensibilidad y la receptividad del educador en su relación con el alumno, 
así como la creatividad y capacidad de improvisación en la tarea educadora. Para Van Manen sería suficiente con acercarse al niño, mostrarle afecto, estar pendiente de él, conocerlo por su nombre, distinguirlo o identificarlo entre el grupo de la clase, saber quién es. La solicitud y el tacto definen toda su pedagogía. Un texto suyo es el mejor exponente:

El profesor de verdad sabe cómo ver a los niños: se percata de la timidez, de un determinado estado de ánimo, de un sentimiento o una expectativa. Para ver realmente de este modo se necesita algo más que ojos. Cuando veo a un niño con el que tengo alguna responsabilidad, le veo con mi cuerpo. En la cualidad sensorial de mis gestos, la forma en que ladeo la cabeza, en determinado movimiento de los pies, mi cuerpo ve la forma en que el niño inicia el día y éste tiene la experiencia de ser visto. De modo que ver de verdad a un niño al principio y al final de cada día es dar a ese niño su lugar en un momento y un espacio específicos $(2003,39)$.

La pedagogía de Van Manen encuentra su lugar en una ética de la responsabilidad que tiene delante al individuo concreto, no abstracto, ni al sujeto ideal. Pero es, al fin, un sujeto "feliz". Y éste, en Schopenhauer, no existe y, por tanto, no puede suscitar compasión.

Desde la ética de Schopenhauer no se justifica, así mismo, una educación moral "indolora", a-pática de raíz kantiana, que nos sitúa ante seres ideales, abstractos, sin contexto ni espacio. La ética formalista kantiana nos ha situado ante los graves problemas que afectan a la humanidad como ante situaciones que teníamos que aprender a resolver mediante el diálogo. El propio Habermas (1991) reconoce, sin embargo, la insuficiencia de la ética dialógica para enfrentarse a las miserias que hoy oscurecen a la Humanidad (la hiriente distribución de la riqueza, la catástrofe medioambiental, la violación generalizada de los derechos humanos, la miseria del Tercer Mundo). Frente a esto, la ética dialógica nada tiene que decir salvo convocar a los afectados a que debatan entre sí. Se supone, por exigencias de unos principios, que el diálogo se produce entre interlocutores en condiciones de igualdad, lo que ha llevado al uso de los mejores argumentos como recurso para la solución de los problemas morales. ¿Y qué pasa con los que no tienen voz, con los que no tienen competencia argumentativa? Simplemente, deben esperar a estar en una posición de igualdad en el diálogo. Y entonces la intervención viene cuando ya es innecesaria (Arteta, 1996). En Schopenhauer, como en los representantes de la Escuela de Frankfurt y en Levinas, la experiencia de sufrimiento del otro es un mandato y una prohibición que se compadece mal con argumentos o ejercicios intelectuales para ir en su ayuda y poner fin a una situación de violencia.

Más que las exigencias de un universalismo formal (la dignidad de la naturaleza humana), como sostiene la ética kantiana, son las experiencias de sufrimiento de individuos y pueblos, socialmente originado, las que interpelan a los individuos a reivindicar el fin de las situaciones que lo provocan (Zamora, 1999). 
El procesalismo a-pático en el que se inscribe la ética dialógica deja fuera de toda posibilidad de interlocución a las víctimas, a los sin voz, que son los primeros que demandan compasión... El ser humano antes que ser hablante es un ser necesitado y sufriente. Y la necesidad y la carencia, la pasión (pati), en definitiva, preceden a la comunicación verbal. Del mismo modo, la comunidad ideal de los sufrientes es previa a la comunidad ideal de los hablantes (Ortega y Mínguez, 2001, 114).

Schopenhauer, en su ética de la compasión, parece adelantarse a Levinas $(1993,82)$ cuando éste escribe: "De ahí la aversión hacia una cierta "predicación" en la que cayó el humanismo occidental... al establecerse en la memorable ambigüedad de las "bellas artes", de las "almas bellas", sin contacto con la realidad de la violencia y de la explotación". Es cierto que la experiencia de cada individuo no es siempre negativa. Pero es en esta experiencia donde se forja el carácter, el temple moral del sujeto.

La ética de Schopenhauer, desde el ejercicio de la compasión con el ser humano concreto, no abstracto, en la experiencia de su vida, podría favorecer la superación de una pedagogía "intelectualista" de los valores. No compadecemos si no es desde y en la experiencia. Es ya un lugar común, en la educación intercultural, por ejemplo, invocar la comprensión intelectual y el respeto a la cultura de los inmigrantes para hacer posible la convivencia y la integración en "nuestra" sociedad de los que vienen de fuera. Se supone que estamos ante "diferencias" culturales y con ellas tenemos que entendernos y convivir, no tanto ante "diferentes por su cultura o etnia", es decir, personas concretas con historias diferentes que nos reclaman nuestro reconocimiento y acogida, no tanto por razón de sus diferencias cuanto por la dignidad de su persona. Ello explica que en la educación intercultural nunca aparezca la pregunta "inoportuna": ¿Por qué emigran las personas? ¿Por qué dejan su tierra, su familia, sus raíces culturales? ¿Por qué la experiencia de desarraigo, de sufrimiento en estas personas concretas? Preguntarse por el otro, por las condiciones de vida que les han empujado a emigrar es contenido irrenunciable de la educación intercultural. Ésta no empieza ni acaba en la "comprensión intelectual" de la cultura del inmigrante. Es antes que nada una pregunta: ¿Por qué? Y si ésta se soslaya, llenaremos las cabezas de informaciones curiosas sobre otras culturas, pero el otro, el diferente cultural será un extraño aventurero o un visitante molesto cuya historia personal permanece desconocida, ignorada para nosotros. Y la integración no afecta sólo a la cultura, es, ante todo, integración de la persona con toda la historia que tiene detrás.

Una educación en valores de corte "intelectualista", cuyo fracaso está suficientemente acreditado (Steiner, 1998), nos ha hurtado la experiencia como locus indispensable en la apropiación de valores. El discurso, la reflexión, la especulación ha suplantado a la realidad de la vida de cada individuo. La urdimbre de la existencia humana, el "mundo de la vida", como contenido educativo, ha sido desplazado o no tenido en consideración, sustituido por el aprendizaje de un conjunto de competencias o saberes intelectuales que se suponen tienen fuerza para orientar la vida moral de todos. Las "cabezas bien amuebladas" podrían ser el objetivo de este tipo 
de educación. Y este enfoque no pertenece al pasado. Goza, por el contrario, de una preocupante actualidad cuando se establece por ley una nueva asignatura para la enseñanza de los valores en las aulas (Bolívar, 2007), como si el mero "conocimiento" de los valores, la "ilustración" ético-moral, fuese suficiente para su apropiación o incorporación a la experiencia, olvidando que "nuestras acciones (morales) no dependen exclusivamente del componente cognitivo del sujeto, de su lógica, de su razón, sino también de nuestros sentimientos" (Bernal, 2003, 147). Es decir, para que los valores se traduzcan en un estilo de vida. La ética de Schopenhauer nos impele a pensar que la tarea de educar no consiste en aplicar principios abstractos previamente establecidos a los que haya que prestar obediencia; que no hay un solo discurso, ni un solo lenguaje, sino múltiples palabras y lenguajes, y nada definitivamente dado.

Que la voluntad pueda dejar de renovar sus voliciones en función de una satisfacción cualquiera, resulta tan inconcebible como que el tiempo pueda tener un principio o un final; no existe nada que pueda colmar para siempre sus anhelos... no admite (la voluntad) bien supremo ni bien absoluto algunos, sino tan sólo un bien relativo y provisional (MCO, 132).

La ética de Schopenhauer aparece descrita con trazos que la identifican "compartiendo la suerte del otro". En las últimas páginas sobre el fundamento de la moral Schopenhauer nos desvela, en un texto aparentemente extraño del filósofo del "Camino hacia el vacío, hacia la nada", la suerte de aquel que liga su vida a la de los demás, la de quien es capaz de ver la realidad desde los otros, saliendo de sí mismo en la compasión. El filósofo del pesimismo afirma que no somos sino esa voluntad que desea ardientemente la vida, que se prolonga en aquellos seres vivos en los que nuestra vida confluye.

Aquel para quien todos los demás eran siempre no-yo; que en el fondo concebía su propia persona como la única verdaderamente real; que a los demás los veía, en cambio, como meros fantasmas a los que atribuía una existencia meramente relativa, en la medida en que podían ser medios para sus fines u oponerse a ellos, de modo que permanecía una diferencia inmensurable, un profundo abismo entre su persona y aquellos no-yoes; que, por tanto, existía exclusivamente en aquella persona propia; ése, en la muerte, vio perecer con su yo toda la realidad y el mundo entero. En cambio, aquel que en todos los demás y hasta en todo lo que tiene vida vio su propio ser, a sí mismo; aquel cuya existencia, por tanto, confluyó con la de todos los vivientes, ése pierde con la muerte sólo una pequeña parte de su existencia: él permanece en todos los demás en los que ha conocido y amado su ser y su propio yo (PFE, 297).

Esta ética nos obliga a asumir que educar es situarse en el otro lado, cruzando la frontera (Bárcena y Mèlich, 2003); que educar obliga a ver la vida desde la otra parte, desde el otro, en la espesura de su vida concreta. 


\section{REFLEXIONES FINALES}

Toda la obra de Schopenhauer es una trabada construcción moral. Su reflexión ética constituye la entraña misma de su pensamiento y es la puerta que abre el camino para la redención del mal radical que hay en el mundo. La lectura del fundamento de la moral de Schopenhauer desemboca en el "misterio" de la compasión que surge de un conocimiento intuitivo superior en cada individuo y que alcanza a la esencia real y única que subyace en cada uno.

Quizá este misticismo ético no satisfaga a los racionalistas que siguen buscando un fundamento puramente racional de la moral. Pero quizá también sea el momento de que la Razón haga cesión de sus privilegios y dé la oportunidad a otras instancias, no menos universales que ella, de demostrar lo que son capaces de hacer en la moral. Entonces tendremos una ética menos racional, pero no por ello menos humana. ¿Pues acaso es más humano el que carece de compasión que el que carece de Razón? (López de Santa María, Introducción, PFE, XI).

La ética schopenhaueriana no establece normas para el buen hacer moral, ni tampoco principios universales que definan el bien y el mal. "No existe ninguna doctrina del deber; ni un principio ético universal; así como tampoco un deber incondicionado" (MCO, 4). La ética para Schopenhauer es una construcción personal que se hace en y desde la experiencia de cada sujeto ante el sufrimiento y carencia del otro. No es, por tanto, un elenco de máximas abstractas que se nos impongan "desde fuera" y a las que todos estaríamos moralmente obligados, situándonos, así, en el reino de la certidumbre y de la seguridad, de la rectitud de nuestra conducta. Más bien Schopenhauer nos instala en la moral de la incertidumbre, de la provisionalidad, de la diversidad de puntos de vista, de la ausencia de autoridades infalibles y fiables, de la inesquivable presencia de la contingencia (Marquard, 2000). Nos devuelve a una educación que debería preparar para caminar con el escaso equipaje del que disponemos "en el umbral de una postmodernidad que nos tiene a la intemperie y nos hurta el amparo de cualquier certidumbre" ( $R$. Aramayo, 2001, XXXVII). La ética de Schopenhauer nos lleva a pensar que la moral no se juega autárquicamente en una razón que se atrinchera contra toda influencia exterior; que rechaza que los sentimientos no pueden participar en la toma de decisiones morales y que éstos deben someter su silencio a la voz única de la razón (Tafalla, 2003). Es, por el contrario, en el mundo de los afectos y de los sentimientos donde construimos nuestra conciencia moral (Buxarrais, 2006). Después de los horrores padecidos por las generaciones de todo el siglo XX, que han puesto en jaque la creencia de que la ciencia podía humanizarnos, se ha desvanecido la esperanza de un dominio racional del hábitat social. La única alternativa, quizá, que nos queda en la mano sea un discurso y una praxis educativa que prepare para la vida, es decir, que cultive la capacidad para vivir cotidianamente en paz con la ambigüedad (Bárcena, 2005). La ética de Schopenhauer se traduce, por tanto, en una pedagogía de la pregunta, de la búsqueda y de la provisionalidad; reclama una 
pedagogía del nómada, porque no hay territorio definitivamente conquistado, ni todo el camino está recorrido. Cuando en la cultura occidental "hay un deseo de dominarlo todo, de explicarlo todo, de poseerlo todo, de reducir todo lo extraño a lo propio, de apropiarse de lo que no tiene sentido conceptual para darle un sentido conceptual" (Mèlich, 2004, 57), la filosofía de Schopenhauer nos devuelve al reino de lo contingente, a lo que se halla «fuera del lenguaje conceptual del Logos, de la Razón, de la Ciencia, de la Tecnología" (Mèlich, 2004, 57).

En educación, como en la vida misma, siempre hay preguntas y respuestas por hacer; nada está definitivamente hecho. Incorporar la ética de Schopenhauer al discurso y práctica pedagógicos implica un nuevo lenguaje y nuevos contenidos, acercarse más a la realidad del hombre de nuestros días. Es decir, "tomarse en serio la inevitable condición histórica del ser humano, impensable fuera o al margen del aquí y del ahora" (Ortega y Mínguez, 2001, 198). Sólo una pedagogía del "aquí y del ahora", situada en el tiempo, alejada de todo idealismo, es capaz de encontrarse con el ser humano concreto que demanda, desde su necesidad y carencia, una respuesta de acogida y de compasión.

\section{BIBLIOGRAFÍA}

Adorno, Th. (1973) Consignas. Buenos Aires, Amorrortu.

- (1975) Dialéctica negativa. Madrid, Taurus.

- (2004) Minima Moralia. Madrid, Akal.

ARTETA, A. (1996) La compasión. Apología de una virtud bajo sospecha. Barcelona, Paidós.

BárCENA, F. (2005) La experiencia reflexiva. Barcelona, Paidós.

BárCena, F. y MèuICH, J. C. (2003) La mirada excéntrica. Una educación desde la mirada de la víctima, en MARDONES, J. M. ${ }^{a}$ y MATE, R. (eds.). La ética ante las víctimas. Barcelona, Anthropos, 195-218.

Bernal, A. (2003) La construcción de la identidad personal como proyecto de educación moral. Supuestos teóricos y delimitación de competencias, Teoría de la Educación. Revista Interuniversitaria, 15, 129-160.

Bolívar, A. (2007) Educación para la ciudadanía. Algo más que una asignatura. Barcelona, Graó.

Buxarrais, M. ${ }^{a}$ R. (2006) Por una ética de la compasión en la educación, Teoría de la Educación. Revista Interuniversitaria, 18, 201-227.

CHAlier, C. (2002) Por una moral más allá del saber. Kant y Levinas. Madrid, Caparrós.

Habermas, J. (1991) Escritos sobre moralidad y eticidad. Barcelona, Paidós-ICE. Universidad de Barcelona.

Horkheimer, M. (1999) Materialismo, metafísica y moral. Madrid, Tecnos. (Del original alemán: Materialismus und metaphysik. Materialismus und Moral. Fischer Verlag, 1988).

LEVINAS, E. (1991) Ética e infinito. Madrid, Visor.

- (1993) Humanismo del otro hombre. Madrid, Caparrós.

LÓPEZ DE SANTA MARÍA, P. (1993) Introducción, en SCHOPENHAUER, A. Los dos problemas fundamentales de la ética. Madrid, Siglo XXI. Traducción, introducción y notas de P. López de Santa María. 
Marquard, O. (2000) Apología de lo contingente. Valencia, Alfons el Magnànim.

MATE, R. (1997) Memoria de Occidente. Barcelona, Anthropos.

MèLıch, J. C. (2004) La lección de Auscbwitz. Barcelona, Herder.

NiETzSCHE, F. (1996) Schopenhauer como educador y otros textos. Barcelona, Círculo de Lectores.

Ortega, P. (2004) La educación moral como pedagogía de la alteridad, Revista Española de Pedagogía, 227, 5-30.

- (2006) Sentimientos y moral en Horkheimer, Adorno y Levinas, Revista Española de Pedagogia, 235, 503-523.

Ortega, P. y Mínguez, R. (2001) La educación moral del ciudadano de hoy. Barcelona, Paidós.

Rodríguez Aramayo, R. (2001) Estudio Preliminar, en Schopenhauer, A. Metafísica de las costumbres. Madrid, Trotta.

SÁNCHEZ, J. J. (2001) Compasión, política y memoria. El sentimiento moral en Max Horkheimer, Isegoria, 25, 223-246.

SCHOPENHAUER, A. (1983) El mundo como voluntad y representación. México, Porrúa. (Del original alemán: Die Welt als Wille und Vorstellung, I, 1988, Brockhaus).

(1993) Los dos problemas fundamentales de la ética. Madrid, Siglo XXI. Traducción, introducción y notas de P. López de Santa María. (Del original alemán: Die beiden Grund probleme der Ethik, 1988, Brockhaus).

- (2001) Metafisica de las costumbres. Madrid, Trotta. Traducción y edición de R. Rodríguez Aramayo. (Del original alemán: Arthur Schopenhauershand schriftlicher Nachlass. Philosophische vorlesungen, X, 1913, Mockrauer).

STEINER, G. (1998) Errata. Madrid, Siruela.

TAfalla, M. (2003) Theodor W. Adorno. Una filosofia de la memoria. Barcelona, Herder.

ZAmora, J. A. (1999) Globalización y cooperación al desarrollo: desafíos éticos, en Foro IGNACIO Ellacuría. La globalización y sus excluidos. Estella-Navarra, Verbo Divino. 